\title{
Wavelet Transform based Broken Rotor-bar Fault detection and Diagnosis Performance Evaluations
}

\author{
Pu Shi \\ Engineering Department \\ Glyndwr University \\ Wrexham, UK
}

\author{
Zheng Chen \\ Engineering Department \\ Glyndwr University \\ Wrexham, UK
}

\author{
Yuriy Vagapov \\ Engineering Department \\ Glyndwr University \\ Wrexham, UK
}

\begin{abstract}
This paper presents the performances evaluation of different wavelet transform under broken rotor bars fault diagnosis. In this report, stator phase current was used for wavelet analysis. Discrete wavelet transform (DWT) coefficients of stator current in a specific frequency band are derived and analyzed. Wavelets $\mathrm{db} 8, \mathrm{db} 9, \mathrm{db} 10, \operatorname{sym} 7$ and sym8 are employed to analyze broken bar distorted stator current. The sensitivities of these wavelets to fault signal are compared and assessed to select the most optimal one. This approach facilitates the detection and diagnosis of broken rotor bar occurrence or even number of broken bars under load variation. Simulation and experimental tests on induction motors with 1, 2, and 3 broken bars cases are conducted and demonstrate the effectiveness of the proposed approach for fault detection.
\end{abstract}

\section{Keywords}

Induction machine, broken rotor bar, DWT, stator current

\section{INTRODUCTION}

It is well known that induction machines play a dominate role in the field of electromechanical energy conversion. Induction machines are widely adopted in a variety of diverse industries product line, ranging from mining industry, process manufacturing, automation applications, heating and air conditioning, transportation, aerospace and marine propulsion applications to the health care industry [1].

Although induction machines are usually well designed and constructed to be robust, however, the possibility of incipient fault is inherent in the machine due to the stresses involved in the conversion of electrical energy to mechanical energy and vice versa. Moreover, internal motor faults (e.g., leads and interturn short circuits, ground faults, bearing and gearbox failures, broken rotor bars and cracked rotor end-rings), as well as external motor faults (e.g., phase failure, asymmetry of main supply and mechanical overload), are expected to happen sooner or later [1]. Therefore, an effective approach for monitoring electrical machines components condition has received considerable attention for many years [2].

Fast Fourier Transforms (FFT) and Wavelet Transforms (WT) are the two most widely used approaches for fault diagnosis of induction machines [3] [4] [5]. FFT is very useful for many steady state applications of the stator current at rated load and speed; however, it is not appropriate to analyze a signal that has transitory characteristics such as drift, abrupt changes, and frequency trends. Besides, it is impossible to estimate the time of the fault occurrence using the FFT [6]. For FFT analysis, the elementary functions are complex exponentials producing the same results for a particular waveform being analyzed. To overcome this problem, short-time Fourier transform (STFT) or windowing techniques was developed to divide the signal into small sections at various time. This approach projects a signal into a time-frequency domain. The STFT represents a sort of compromise between time and frequency based views of a signal and it provides some information about both. However, this technique offers limited precision information and is depended on the size of the window. Moreover, the fixed window size is the kernel issue when STFT is used. [7]

The wavelet transform was introduced with the idea of overcoming the difficulties mentioned before. In wavelet analysis, the fundamental functions could be any permissible mother wavelets and the results produced are unique to the selected wavelet. A windowing technique with variable size region is used to perform the signal analysis, which will be stator current in this paper. Wavelet analysis allows the use of long time intervals where more precise low frequency information is wanted, and shorter regions where high frequency information is desired. In Douglas and Pillay [8], it has been shown that use of high-order wavelets can improve the accuracy of diagnosis of the broken rotor bars. In Ye, et al. [9], wavelet packet decomposition of the stator current is used for online noninvasive detection of broken rotor bars. In Daviu, et al. [10], the evolution of certain frequency components associated with broken rotor bars, during the start-up transient mode has been extracted.

In spite of satisfactory performance of DWT, it has some drawbacks. Selection of optimal mother wavelet is somewhat arbitrary, not a known priori which may introduce error in the detection parameters. Besides, the overlap between bands associated with wavelet signals appearing mainly for lower order wavelet. In this paper, the proposed approach is focused on the study of different wavelet performance by analysis the coefficients derived from the DWT [11] [12]. A best representative wavelet is chose for rotor fault detection by comprehensive analysis these coefficients. This allows a good interpretation of the phenomenon due to the variation of these signals reflects clearly the evolution of the harmonics associated with broken rotor bars during the transient. Moreover, the use of the wavelet signals (approximation and high-order details) resulting from the DWT constitutes an interesting advantage because these signals act as filters, according to Mallat algorithm, allowing the automatic extraction of the time evolution of the low frequency components that are presented in the signal during the transient [13]. Comparing to traditional signal processing techniques, the computation time required for DWT analysis is negligible due to the proposed technique does not use any intricate algorithm for the extraction of the evolution of the signal components. 
The approach for the diagnosis of broken rotor bars is described and applied to industrial induction machines. This new approach is also compared with the well-known method, based on the FFT analysis of the stator current in steady state. Several experiments are developed for different fault cases and operating conditions such as one-bar breakage, two-bar breakages and also variation rated load. For the purposes of testing, the bar breakages were forced in the workshop in industrial motors to compare machine behavior in healthy and faulty conditions.

\section{EXPERIMENTAL SETUP}

In this section, an on-line experimental rig is developed based on the proposed approach in order to test and verify the performance of the diagnosis system. The on-line current monitoring system is shown in Figure1. The experiment is carried out under the self-designed test rig which is mainly composed a set of three phase induction machines, DC generate, current transducer, A/D converter, and computer. Firstly, transient stator current signals are collected from tested motors and signal preprocessing is conducted which contains smoothing and subtraction. Moreover, Matlab \& Wavelet toolbox is used to decompose the acquired time domain signal into time-frequency domain. Then, fault features frequency band is extracted from all specified wavelet transform level. Finally, the individual diagnosis results are used to validate the developed model.

The tested motors are three identical three-phase, 2-pole, 36 stator slots and 28 rotor slots induction machines. The specifications of the proposed induction motors used in our experiment are summarized in Table 1. The tests are carried out on a healthy motor and a motor with bored bars. The rotor bar breakages were broken deliberately by drilling holes in workshop.

Table 1. Induction motor Characteristics used in the experiment

\begin{tabular}{|c|c|}
\hline Description & Value \\
\hline Power & $5.5 \mathrm{KW}$ \\
\hline Input Voltage & $240 / 380 \mathrm{~V}$ \\
\hline Full load current & $20.6 / 11.9 \mathrm{~A}$ \\
\hline Supply Frequency & $50 \mathrm{~Hz}$ \\
\hline Number of poles & 2 \\
\hline Number of stator slots & 36 \\
\hline Number of rotor slots & 28 \\
\hline Speed & $3000 \mathrm{rpm}$ \\
\hline
\end{tabular}

Stator currents of the motor are sampled by a current Hall Effect sensor which is placed in one of the phase line current cables. The stator current is sampled with a $1.92 \mathrm{KHz}$ rate and interfaced to a PC by an ADC-11 data acquisition system. The quantities have been measured for healthy and three broken rotor bars at varied load.

The motor load is controlled through the generator shaft speed. A DC generator is coupled to the motor as the load. The excitation current of the generator has been adjusted in order to regulate the output voltage. A high power resistance box has been connected to the terminals of the generator. The resistance of this box can be selected step by step by a selector on the box. By regulating the output voltage of the generator inserted in the excitation current pass, the load level can be regulated precisely.

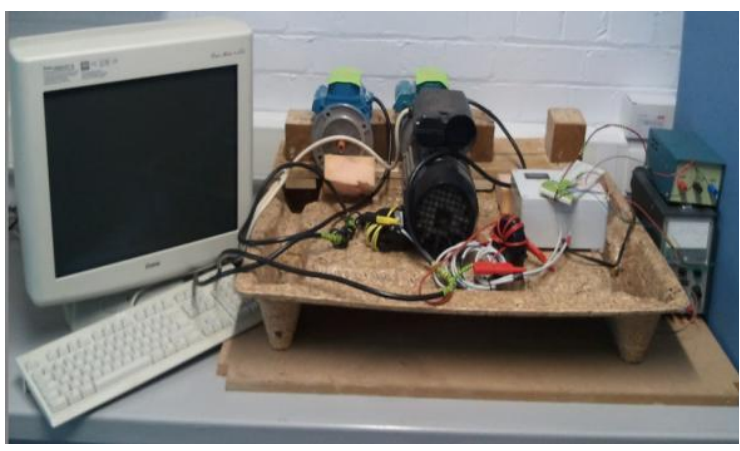

Fig 1. View of the experimental setup and broken rotor bars

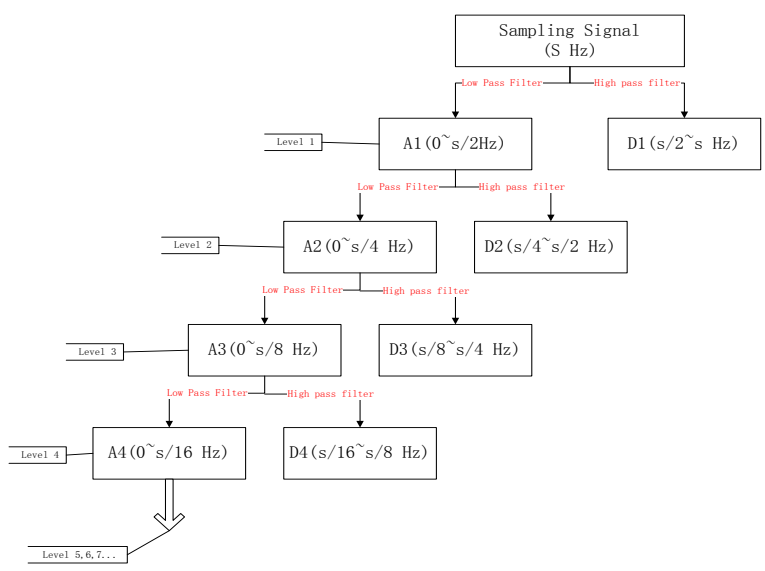

Figure 2. Demonstration of DWT

\section{DISCRETE WAVELET TRANSFORM}

\subsection{Bases of DWT}

The principle idea that underlies the application of DWT is the dyadic bandpass filtering process carried out by this transformation. Provided a certain sampled signal $S=\left(i_{1}, i_{2}\right.$, . $\left.\ldots, i_{N}\right)$, the DWT decomposes it onto several wavelet signals (an approximation signal $a_{n}$ and $n$ detail signals $d_{j}$ ) [10] [14]. A certain frequency band is associated with each wavelet signal; the wavelet signal reflects the time evolution of the frequency components of the original signal $S$, which are contained within its associated frequency band as shown in Figure 2 [10].

The decomposition coefficients can be determined through convolution and implemented by using a filter [13]. The filter, LPF represents a low-pass filter and HPF represents a highpass filter. The decomposition process can be iterated, with successive approximations being decomposed in turn, so that one signal is broken down into many lower resolution components.

More concretely, if $f_{s}$ (in samples per second) is the sampling rate used for capturing $S$, then the detail $d_{j}$ contains the information concerning the signal components with frequencies included in the interval

$$
\mathrm{f}\left(\mathrm{d}_{\mathrm{j}}\right) \in\left[2^{-(\mathrm{j}+1)} \cdot \mathrm{f}_{\mathrm{s}}, 2^{-\mathrm{j}} \cdot \mathrm{f}_{\mathrm{s}}\right] \mathrm{Hz}
$$

The approximation signal an includes the low-frequency components of the signal belonging to the interval

$$
\mathbf{f}\left(\mathrm{a}_{\mathrm{n}}\right) \in\left[\mathrm{O}, 2^{-(\mathrm{n}+1)} \cdot \mathbf{f}_{\mathrm{s}}\right] \mathrm{Hz}
$$


Due to the automatic filtering performed by the wavelet transform, this tool provides a very attractive flexibility for the simultaneous analysis of the transient evolution of rather different frequency components present in the same signal. At the same time, in comparison with other tools, the computational requirements are low. In addition, the DWT is available in standard commercial software packages, so no special or complex algorithm is required for its application.

\subsection{Some Considerations about DWT Parameters}

In this paper, Matlab Wavelet Toolbox is used to analyze signals, although other software packages could perfectly be suitable for applying the methodology. Prior to the application of the DWT, some considerations have to be done regarding the different parameters of the DWT decomposition, such as the type of mother wavelet, the order of the mother wavelet, or the number of decomposition levels.

\subsubsection{Selection of Mother Wavelet}

With regarding to the DWT, an important step is the selection of the mother wavelet to carry out the analysis. The selected mother wavelet is related to the coefficients of the filters used in the filtering process inherent to the DWT [14]. During these last decades, several wavelet families with rather different mathematical properties have been developed. Infinite supported wavelets (Gaussian, Mexican Hat, Morlet, Meyer, etc.) and wavelets with compact support (orthogonal wavelets such as Daubechies or Coiflet, and biorthogonal wavelets) have been proposed [15]. In some fields of science, some families have shown better results for particular applications.

Nevertheless, regarding the transient extraction of fault components, the experience achieved after the development of multiple tests shows that a wide variety of wavelet families can lead to satisfactory results.

However, it has to be remarked that, in the case of compactly supported wavelets, once the wavelet family is selected, it is advisable to carry out the DWT using a high-order mother wavelet, this is, a wavelet with an associated filter with a large number of coefficients. If a low-order wavelet is used, the frequency response gets worse, and the overlap between adjacent frequency bands increases. Daubechies or Symlet with high orders has shown satisfactory results. In addition, dmeyer, within the infinite support wavelets, has behaved very well.

In this paper, Daubechies 8, 9, 10 and Symlet 7, 8 have been selected as the mother wavelets used for the DWT analyses. Figure 3 shows wavelet family of Daubechies or Symlet.

\subsubsection{Specification of the Number of Decomposition Levels}

The number of decomposition levels is determined by the low frequency components to be traced. The lower the frequency components to be extracted, the higher the number of decomposition levels of the DWT [13]. So, the evolution of these components will be reflected through the high-level signals resulting from the analysis.

Typically, for the extraction of the frequency components caused by rotor asymmetries or even eccentricities, the number of decomposition levels should be equal or higher than that of the detail signal containing the fundamental frequency.

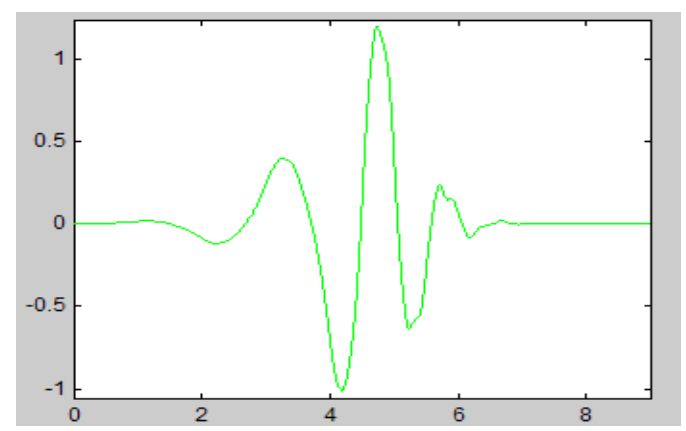

a. Db Wavelet

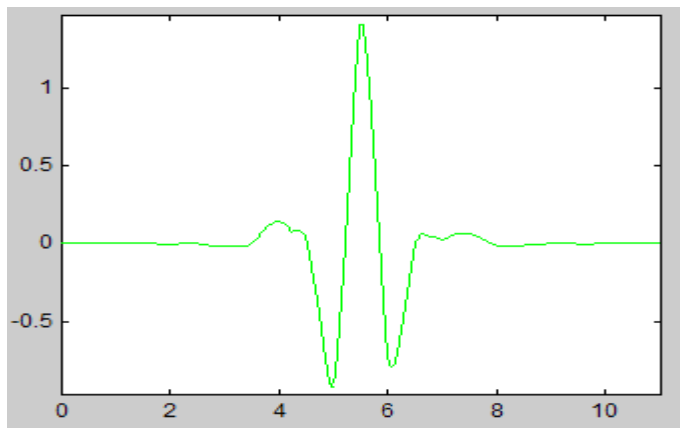

b. Sym Wavelet

Fig 3. Demonstration of wavelet family

Finally, the number of decomposition levels $n_{d}$ is related to the sampling frequency of the signal being analyzed (i.e., $f_{s}$ ). This parameter has to be chosen in such a way that the DWT supplies at least three high-level signals (i.e., two details and an approximation) with frequency bands below the supply frequency $f$; the following condition applies [13]:

$$
n_{d} \geq n_{f}+2
$$

$n_{f}$ being the level of the detail that contains the supply frequency, which can be calculated using (4), i.e.,

$$
2^{-\left(n_{d}+1\right)} \cdot f_{s}<f
$$

This condition means that the lower limit of the frequency band of the $n_{f}$ level detail is lower than the supply frequency. Thus

$$
n_{d}>\frac{\log \left(f_{s} / f\right)}{\log (2)}+1
$$

(Integer)

Figure 2 illustrates the implementation procedure of a Discrete Wavelet Transform (DWT), in which $S$ is the original signal, LPF and HPF are the low-pass and high-pass filters respectively. It must be considered, when capturing the transient signal, that the sampling frequency $f_{s}$ plays an important role. Taking into account the Nyquist criterion, a very high sampling frequency is not mandatory for the application of the method, since most of the important fault components are usually in the low-frequency region [10].

Another practical remark is that, due to the nonideal filtering carried out by the wavelet signals, it is advisable not to set the limits of the band of the wavelet signal containing the fundamental frequency $f_{s}$ very close to this frequency. Otherwise, this component could partially be filtered within the adjacent bands, masking the evolution of other components within these bands due to its much higher 
amplitude. Sampling frequencies of 1920 samples/s which enable good resolution analyses and, according to (6) and (7), Table 2 shows the frequency levels of the wavelet function coefficients.

Table 2. Frequency levels of wavelet coefficients

\begin{tabular}{cc}
\hline $\begin{array}{c}\text { Wavelet } \\
\text { Analysis }\end{array}$ & $\begin{array}{c}\text { Frequency } \\
\text { Components (Hz) }\end{array}$ \\
\hline A5 & $0-30$ \\
D5 & $30-60$ \\
D4 & $60-120$ \\
D3 & $120-240$ \\
D2 & $240-480$ \\
A1 & $480-960$ \\
\hline
\end{tabular}

Once the mother wavelet and the number of decomposition levels have been selected, it is possible to carry out the DWT of the analyzed signal, obtaining wavelet decomposition graphics as those shown in Figures 5-9.

\section{SPECTRUM ANALYSIS OF STATOR CURRENT UNDER VARYING LOAD}

When an induction motor under normal operation, frequency of the rotor induced current is equal to $s f_{s}$. This current generates a forward rotating magnetic field with respect to the rotor. If the rotor operates under one broken bar, the induced rotor current with frequency $s f_{s}$ consists of two forward and backward magnetic components that generate the magnetic fields with speed $\mathrm{s} \pm s f_{s}$ regarding to the rotor. If the speeds of these fields are added up with the rotor speed equal to $(1-s) f_{s}$ the speed of these fields with respect to the stator winding is as follows [13]:

$$
\begin{gathered}
s f_{s}+(1-s) f_{s}=f_{s} \\
-s f_{s}+(1-s) f_{s}=(1-2 s) f_{s}
\end{gathered}
$$

Considering (7), a current with frequency $(1-2 s) f_{s}$ is induced in the stator winding. The interaction between the backward field of the rotor and the stator field leads to some ripples on the stator current as shown in Figure 4. The relative speed between the rotor and stator fields is equal to $2 s f_{s}$ as follows:

$$
f_{s}-(1-s) f_{s}=2 s f_{s}
$$

This oscillation in the rotor speed produces a current with frequency $3 s f_{s}$ in the rotor and similar with the previous case. According to (9) and (10), a current with frequencies $(1+2 s) f_{s}$ and $(1-4 s) f_{s}$ are induced in the stator.

$$
\begin{aligned}
& 3 s f_{s}+(1-s) f_{s}=(1+2 s) f_{s} \\
& -3 s f_{s}+(1-s) f_{s}=(1-4 s) f_{s}
\end{aligned}
$$

Therefore, when rotor bars broken happen, harmonic components of stator current having patterns as: $f_{s} \pm 2 f_{s}, f_{s} \pm 4 f_{s}$, $f_{s} \pm 6 f_{s} \ldots$ or in general harmonic with frequencies $(1 \pm 2 K s) f_{s}$ or $f_{s} \pm 2 K f_{s}$ are induced in the stator current. Therefore, considering the increase of the amplitudes of the harmonic components in $(1 \pm 2 K s) f_{s}$ due to fault and its extension. The quantities have been measured for 1,2 and 3 broken rotor bars and 3 broken bars in practical. Moreover, the frequency bands around the fundamental component of current must be concentrated on for diagnosis of the broken rotor bars.

By taking into account the above facts and Nyquist sampling theorem, the chosen sampling frequency of the signal in this research was chosen to be $1920 \mathrm{~Hz}$. Frequency spectrums of the stator current for a healthy motor and a motor with 1,2 and 3 broken bars were presented in Figure 5 (a-e). Taking comparison from Figure 5(a) to Figure 5 (e) indicates that 3 broken bars increase the harmonic components $(1 \pm 2 s) f_{s}$ from $89 d B$ in the healthy to $-71 d B$ in the faulty motor under load variation. Table 3 shows the measured amplitudes of harmonic components of $(1 \pm 2 s) f_{s}$ for healthy and faulty motor with 1,2 and 3 broken rotor bars and 3 broken bars in experimental.

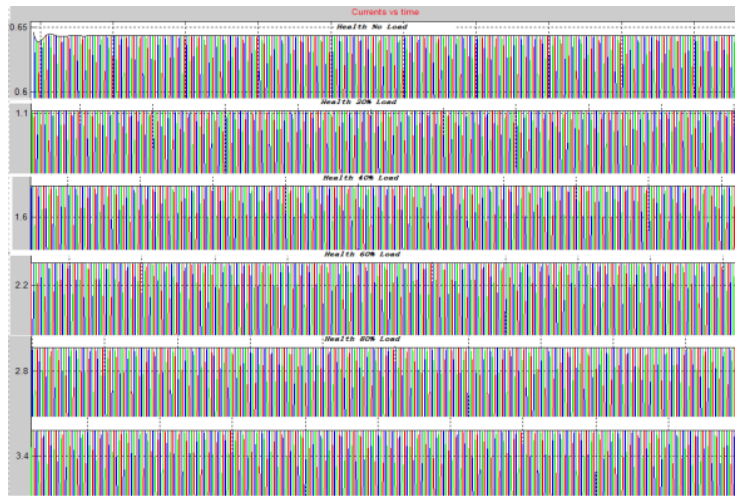

(a). Healthy

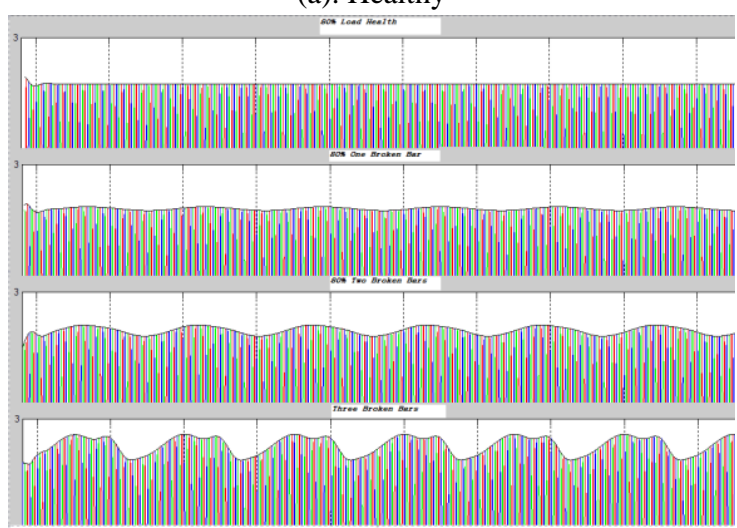

(b). Two broken bars

\begin{tabular}{|c|c|c|c|c|}
\hline $\begin{array}{c}\text { No of } \\
\text { broken } \\
\text { bar }\end{array}$ & $\begin{array}{l}\text { Amplitude } \\
\text { of }(1-2 s) f_{s}\end{array}$ & $\begin{array}{l}\text { Amplitude } \\
\text { of }(1+2 s) f_{s}\end{array}$ & $\begin{array}{l}\text { Frequency } \\
\text { of }(1-2 s) f_{s}\end{array}$ & $\begin{array}{l}\text { Frequency } \\
\text { of }(1+2 s) f_{s}\end{array}$ \\
\hline $\mathbf{0}$ & -89 & -89 & $49 \mathrm{~Hz}$ & $51 \mathrm{~Hz}$ \\
\hline 1 & -77 & -77 & $48 \mathrm{~Hz}$ & $52 \mathrm{~Hz}$ \\
\hline 2 & -75 & -75 & $47 \mathrm{~Hz}$ & $53 \mathrm{~Hz}$ \\
\hline 3 & -71 & -71 & $46 \mathrm{~Hz}$ & $54 \mathrm{~Hz}$ \\
\hline $3(\operatorname{Exp})$ & -70 & -70 & $46 \mathrm{~Hz}$ & $54 \mathrm{~Hz}$ \\
\hline
\end{tabular}

Fig 4. Demonstration of stator current under varying load for health and two broken rotor bar $(60 \%$ Load).

Table 3. Amplitudes of harmonic components for healthy and faulty motor in experimental

Referring to Figures 5(a-e) the higher broken bar numbers increase the amplitude of harmonic components $(1 \pm 2 \mathrm{~s}) \mathrm{f}_{\mathrm{s}}$. An interesting point in Table 3 that broken bar numbers not only affect the amplitude of the harmonic components but also 
influence the frequency of the harmonic components, as such that difference between the frequencies of harmonic components due to broken bars increase comparing with the fundamental frequency. The reason is that higher broken bars numbers decreases the speed of the motor and slip and difference of frequencies $(1 \pm 2 \mathrm{~s}) \mathrm{f}_{\mathrm{s}}$ in respect to the fundamental frequency rises. Table 3 summarizes the frequency of harmonic components $(1 \pm 2 \mathrm{ks}) \mathrm{f}_{\mathrm{s}}$ for $\mathrm{k}=1,2$ of healthy and faulty motor with 1,2 and 3 broken bars under rate load.

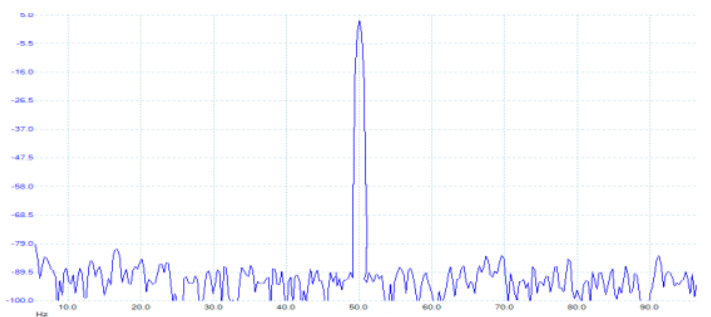

(a). Healthy

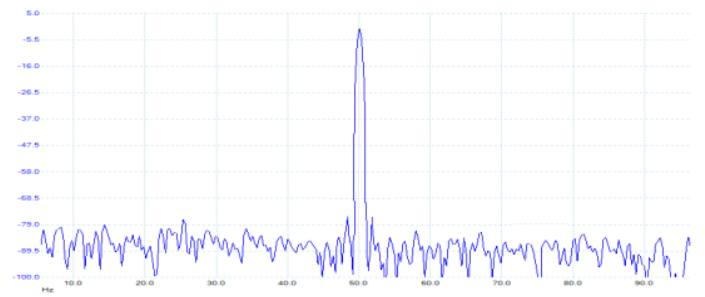

(b). One broken bar

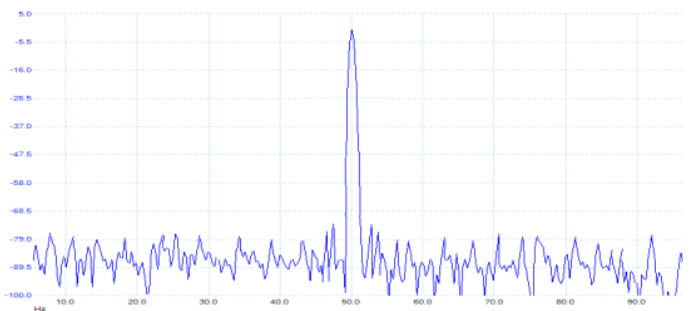

(c). Two broken bars

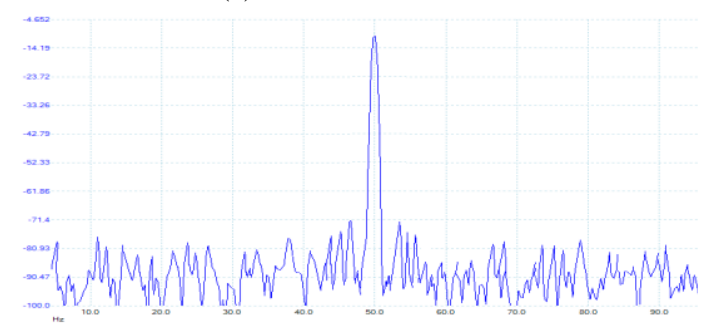

(d). Three broken bars

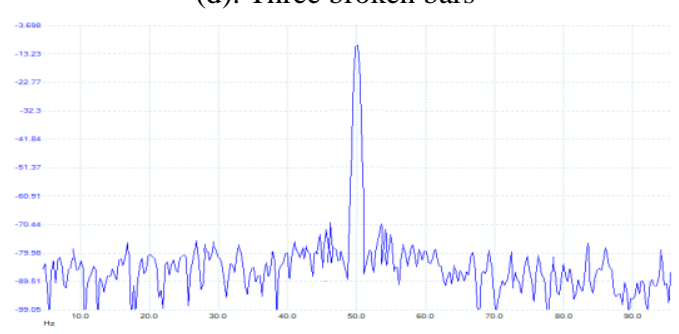

(e).Three broken bars experiment

Fig 5. Normalized line current spectra of a faulty induction motor with four broken rotor bars: (a-d) Simulation, (e) Experimental

\section{INTRODUCING INDICES FOR DIAGNOSIS OF FAULT AND NUMBER OF BROKEN ROTOR BARS}

As previously discussed, Rotor broken bars generate side band components around the fundamental frequency. Moreover, referring to Table 2 indicates that wavelet coefficients in D5 consist of side band components around the fundamental frequency. Therefore, in this paper, a different wavelet $(d b 8,9,10$, sym 7,8$)$ coefficient in $D 5$ has been used to diagnose the fault and number of the broken bars. By comparing these coefficients in D5, the optimal wavelet was selected for diagnosis of rotor fault and number of broken bars.

In Figure 6, the wavelets coefficients in D5 for a healthy motor are presented. Figure 7 presents the wavelet coefficients in D5 for a motor with one broken rotor bar. Figure 8 demonstrates the wavelets coefficients in $D 5$ for a motor with two broken rotor bars. Figure 9 shows the wavelets coefficients in D5 for a motor with three broken rotor bars. To validate the simulation results, experimental results was presented in Figure 14.

Figure 6-10 and Table 5-9 shows the different wavelet coefficients in $D 5$ for a healthy motor by using $d b 8,9,10$, sym 7, 8 wavelets. Normal data analysis approaches, such mean stator current, standard deviation (STD) and average of D5 wavelet coefficients fluctuations were calculate to represent the features in a numerical way. In the end, two novel indexes were introduced as criterion function to diagnose the breakage in rotor bars.

For mean stator current analysis, comparison of wavelet coefficients of its amplitude in D5 for the healthy motor and motor with 1,2 and 3 broken rotor bar confirms the increase of the oscillation due to the harmonic components $(1 \pm 2 K s) f_{s}$ in the stator current. Figure 6-10 and Table 5-9 indicate that the average value of the current amplitude is reduced due to the broken rotor bars, such that the current decreases from $4.3939 A$ in $d b 8,(4.3998 A$ in $d b 9,4.4215 A$ in $d b 10,4.4326 A$ in sym $7,4.4628 \mathrm{~A}$ in sym8), in the healthy motor to $4.1395 \mathrm{~A}$, $(4.1563 A, 4.1632 A, 4.2356 A, 4.2521 A)$ in the motor with one broken bars under same wavelet analysis. By increasing the number of broken bars to two, this value is decreased to $3.9355 A$, (3.9856A, 3.9875A, 3.9921A, 3.9987A). Finally for a motor with 3 broken bars this reduces to 3.7793A, (3.7919A, $3.7965 \mathrm{~A}, 3.8016 \mathrm{~A}, 3.8109 \mathrm{~A})$. The trend of this reduction continues by increasing the number of the broken bars.

In addition, the standard deviation (STD) value of wavelet coefficients in D5 increases from 2.1131, 2.1157, 2.1161, $2.1177,2.1186$ in the healthy motor to $2.1323,2.1325$, $2.1357,2.1362,2.1368$ in a motor with one broken rotor bar under $\mathrm{db} 8, \mathrm{db} 9 \mathrm{db} 10, \mathrm{sym} 7$, sym8. By increasing the number of broken rotor bars to two, this STD increases to 2.1679, $2.1686,2.1689,2.1697,2.1712$. This change relates to the harmonic components in the stator current, which causes oscillation in D5. The STD value of the wavelet coefficients in D5 increases to 2.1869, 2.1889, 2.1896, 2.1908, 2.1911 for 3 broken bars.

Furthermore, average of fluctuations in absolute value of the wavelet coefficients in D5 increases from $0.0769,0.0782$, $0.0782,0.0783,0.0789$ in the healthy motor to 0.0897 , $0.0895,0.0899,0.0901,0.0913$ in a faulty motor with 1 broken bar of rated load in $d b 8, d b 9 d b 10, \operatorname{sym} 7, \operatorname{sym} 8$. Referring to Table 7, an increase is seen in fluctuations 
average of absolute value $0.1235,0.1296,0.1311,0.1357$, 0.1388 of the wavelet coefficients in $D 5$, by increasing the broken number to 3 this fluctuations average in absolute value of the coefficients increases to $0.1635,0.1696,0.1711$, $0.1757,0.1788$.

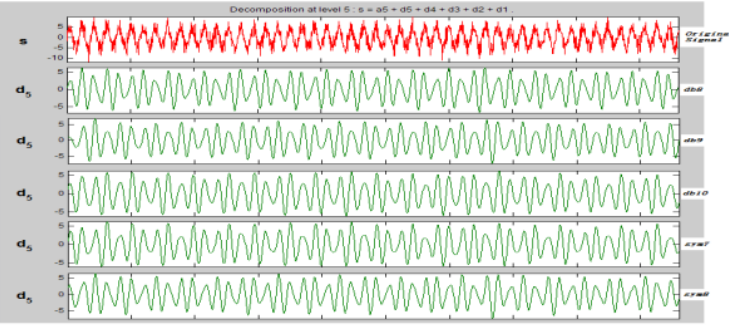

Fig 6. Wavelets coefficients for healthy motor.

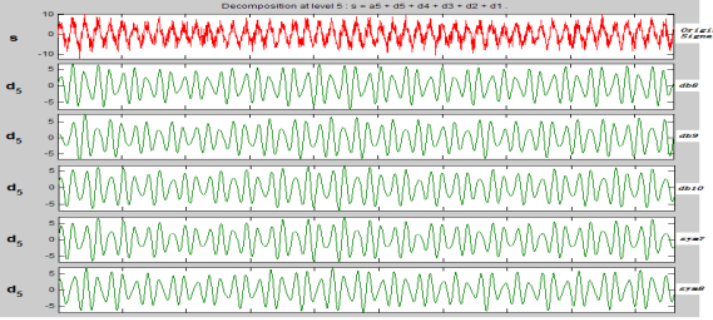

Fig 7. Wavelets coefficients for one broken rotor bar.

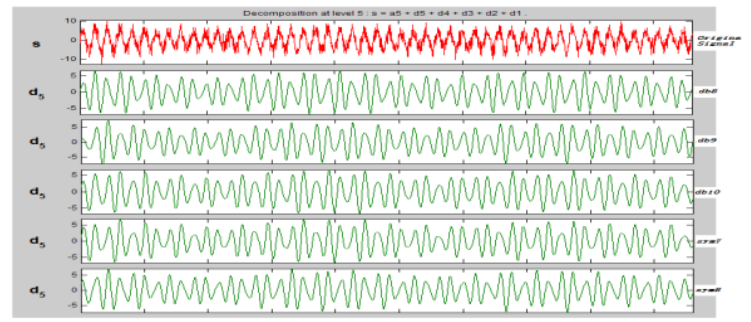

Fig 8. Wavelets coefficients for two broken rotor bars.

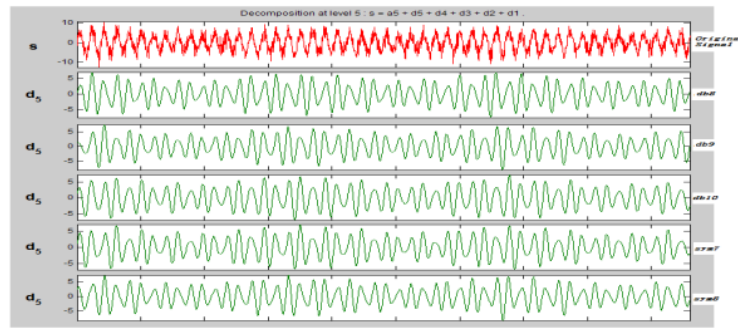

Fig 9. Wavelets coefficients for three broken rotor bars.

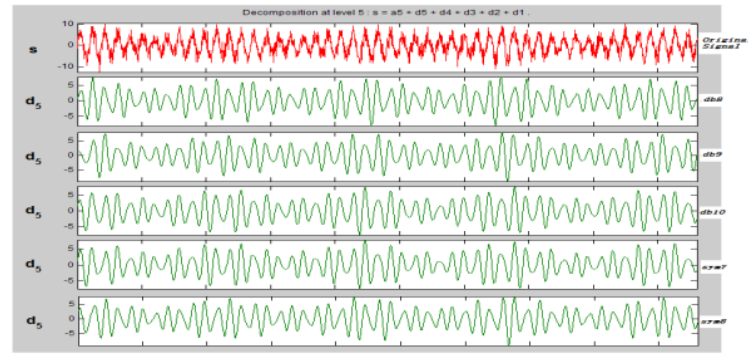

Fig 10. Different Wavelets coefficients in D5 for two broken rotor bar motor under experimental results.
Table 4. Criterion function for different wavelets under healthy condition

\begin{tabular}{|c|c|c|c|c|c|}
\hline $\begin{array}{c}\text { Wavele } \\
\text { ts }\end{array}$ & $\begin{array}{c}\text { Mea } \\
\mathbf{n}\end{array}$ & STD & $\begin{array}{c}\text { Mean } \\
\text { fluctuatio } \\
\text { ns }\end{array}$ & Index1 & Index2 \\
\hline Db8 & 4.393 & 2.113 & 0.0769 & 0.4809167 & 0.0175015 \\
& 9 & 1 & & 25 & 36 \\
\hline Db9 & 4.399 & 2.115 & 0.0782 & 0.4808627 & 0.0177735 \\
& 8 & 7 & & 66 & 35 \\
\hline Db10 & 4.421 & 2.116 & 0.0782 & 0.4785932 & 0.0176863 \\
& 5 & 1 & & 38 & 06 \\
\hline Sym7 & 4.432 & 2.117 & 0.0783 & 0.4777557 & 0.0176645 \\
& 6 & 7 & & 19 & 76 \\
\hline Sym8 & 4.462 & 2.118 & 0.0789 & 0.4747243 & 0.0176794 \\
& 8 & 6 & & 88 & 84 \\
\hline
\end{tabular}

Table 5. Criterion function for different wavelets under one broken bar

\begin{tabular}{|c|c|c|c|c|c|}
\hline $\begin{array}{c}\text { Wavele } \\
\text { ts }\end{array}$ & $\begin{array}{c}\text { Mea } \\
\mathbf{n}\end{array}$ & STD & $\begin{array}{c}\text { Mean } \\
\text { fluctuatio } \\
\text { ns }\end{array}$ & Index1 & Index2 \\
\hline Db8 & 4.199 & 2.121 & 0.1097 & 0.5051077 & 0.0261221 \\
& 5 & 2 & & 51 & 57 \\
\hline Db9 & 4.196 & 2.122 & 0.1095 & 0.5058027 & 0.0260944 \\
& 3 & 5 & & 31 & 17 \\
\hline Db10 & 4.173 & 2.205 & 0.1221 & 0.5285392 & 0.0292581 \\
& 2 & 7 & & 5 & 23 \\
\hline Sym7 & 4.195 & 2.136 & 0.1001 & 0.5091524 & 0.0238583 \\
& 6 & 2 & & 45 & 28 \\
\hline Sym8 & 4.182 & 2.203 & 0.1173 & 0.5268884 & 0.0280481 \\
& 1 & 5 & & 05 & 1 \\
\hline
\end{tabular}

Table 6. Criterion function for different wavelets under two broken bars

\begin{tabular}{|c|c|c|c|c|c|}
\hline $\begin{array}{c}\text { Wavele } \\
\text { ts }\end{array}$ & $\begin{array}{c}\text { Mea } \\
\mathbf{n}\end{array}$ & STD & $\begin{array}{c}\text { Mean } \\
\text { fluctuatio } \\
\text { ns }\end{array}$ & Index1 & Index2 \\
\hline Db8 & $\begin{array}{c}3.995 \\
5\end{array}$ & $\begin{array}{c}2.167 \\
9\end{array}$ & 0.1235 & $\begin{array}{c}0.5425854 \\
09\end{array}$ & $\begin{array}{c}0.0309097 \\
73\end{array}$ \\
\hline Db9 & $\begin{array}{c}3.985 \\
6\end{array}$ & $\begin{array}{c}2.168 \\
6\end{array}$ & 0.1296 & $\begin{array}{c}0.5441087 \\
92\end{array}$ & $\begin{array}{c}0.0325170 \\
61\end{array}$ \\
\hline Db10 & $\begin{array}{c}3.897 \\
5\end{array}$ & $\begin{array}{c}2.168 \\
9\end{array}$ & 0.1311 & $\begin{array}{c}0.5564849 \\
26\end{array}$ & $\begin{array}{c}0.0336369 \\
47\end{array}$ \\
\hline Sym7 & $\begin{array}{c}3.992 \\
1\end{array}$ & $\begin{array}{c}2.169 \\
7 \\
\end{array}$ & 0.1357 & $\begin{array}{c}0.5434984 \\
09\end{array}$ & $\begin{array}{c}0.0339921 \\
34\end{array}$ \\
\hline Sym8 & $\begin{array}{c}3.988 \\
7\end{array}$ & $\begin{array}{c}2.171 \\
2\end{array}$ & 0.1388 & $\begin{array}{c}0.5443377 \\
54\end{array}$ & $\begin{array}{c}0.0347983 \\
05\end{array}$ \\
\hline
\end{tabular}

Table 7. Criterion function for different wavelets under three broken bars

\begin{tabular}{|c|c|c|c|c|c|}
\hline $\begin{array}{c}\text { Wavele } \\
\text { ts }\end{array}$ & $\begin{array}{c}\text { Mea } \\
\mathbf{n}\end{array}$ & STD & $\begin{array}{c}\text { Mean } \\
\text { fluctuatio } \\
\text { ns }\end{array}$ & Index1 & Index2 \\
\hline Db8 & 3.779 & 2.186 & 0.1635 & 0.5786521 & 0.0432619 \\
& 3 & 9 & & 31 & 8 \\
\hline Db9 & 3.791 & 2.188 & 0.1696 & 0.5772567 & 0.0447269 \\
& 9 & 9 & & 84 & 18 \\
\hline Db10 & 3.796 & 2.189 & 0.1711 & 0.5767417 & 0.0450678 \\
& 5 & 6 & & 36 & 26 \\
\hline Sym7 & 3.801 & 2.190 & 0.1757 & 0.5762836 & 0.0462173 \\
& 6 & 8 & & 7 & 82 \\
\hline Sym8 & 3.810 & 2.191 & 0.1788 & 0.5749560 & 0.0469180 \\
& 9 & 1 & & 47 & 51 \\
\hline
\end{tabular}

Through the numerical analysis of mean, STD and fluctuations, the change trends can be developed when broken rotor bars occurring in induction motor. However, these trends 
are not easy for operator to judge due to the values are too small to tell the difference. To solve this problem, according to the above mentioned facts the following indexes is proposed for diagnosis of the broken bar:

$$
\begin{aligned}
& \text { Criterion function } 1=\frac{\text { STD }}{\text { mean }} \\
& \text { Criterion function2 }=\frac{\text { Fluctuation coefficients }}{\text { Mean }}
\end{aligned}
$$

where the average of absolute value of the wavelet coefficients in D5 is expressed in per-unit with respect to the average amplitude of the corresponding currents. The value of index 1 increases by occurring the breaking in the bars of the rotor and has ascending trend as shown in Figure 11. According to Table 4-8, the value of index 1 for a healthy motor is $47-48 \%$ and for the motor with one broken rotor bar is $50-51 \%$. A noticeable difference between these values makes the proposed index enable to diagnose faulty motor from healthy one. On the other hand, comparison of this index for one and two broken bars indicates that this index is also a very good criterion for the diagnosis of the broken rotor bars. It is a convenient index for diagnosis of the number of broken bars.

Table 8. Criterion function for different wavelets for three broken bars under experimental results

\begin{tabular}{|c|c|c|c|c|c|}
\hline $\begin{array}{c}\text { Wavele } \\
\text { ts }\end{array}$ & $\begin{array}{c}\text { Mea } \\
\mathbf{n}\end{array}$ & STD & $\begin{array}{c}\text { Mean } \\
\text { fluctuatio } \\
\text { ns }\end{array}$ & Index1 & Index2 \\
\hline Db8 & $\begin{array}{c}4.179 \\
3\end{array}$ & $\begin{array}{c}2.436 \\
9\end{array}$ & 0.1935 & 0.5830880 & 0.0462996 \\
& & 77 & 2 \\
\hline Db9 & 4.191 & 2.438 & 0.1996 & 0.5818125 & 0.0476156 \\
& 9 & 9 & & 43 & 4 \\
\hline Db10 & 4.196 & $\begin{array}{c}2.439 \\
6\end{array}$ & 0.2011 & 0.5813415 & 0.0479208 \\
& 5 & 6 & & 94 & 86 \\
\hline Sym7 & 4.201 & 2.440 & 0.2057 & 0.5809215 & 0.0489575 \\
& 6 & 8 & & 54 & 4 \\
\hline Sym8 & 4.210 & 2.441 & 0.2088 & 0.5797098 & 0.0495855 \\
& 9 & 1 & & 01 & 99 \\
\hline
\end{tabular}

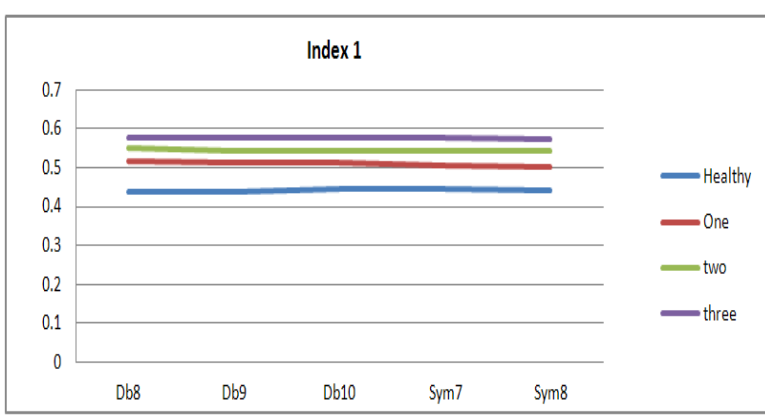

Fig 11. Criterion function of index 1.

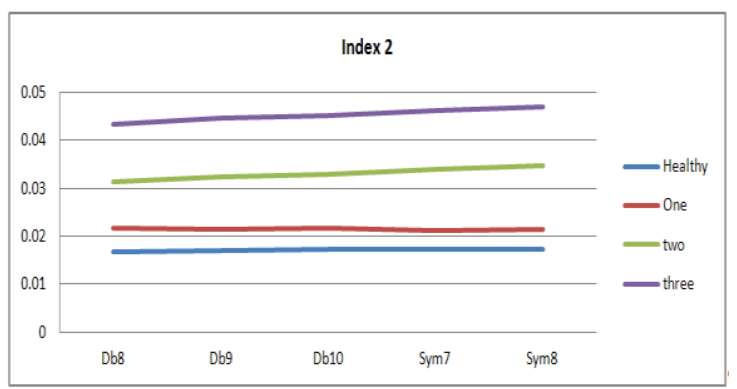

Fig 12. Criterion function of index 2.
In Table 4-8, values of Index 2 for different number of broken bars have been mentioned in Figure 12. It is observed that index 2 increases from $2.1 \%$ in one broken bar to $3.1-3.4 \%$ in two broken bars. Also this index increases from $3.1-3.4 \%$ in 2 broken bars to $4.3-4.6 \%$ in 3 broken bars.

Figure 10 shows the experimental for 3 rotor broken bars which are in good agreement with the simulation results. Although by introducing these two indexes, boundaries between healthy and faulty even numbers of broken bars clearly showed in Figure 11, 12. There does still exist a problem, gap values between these boundaries are too small to diagnosis. To increase the accuracy of diagnosis, the most suitable wavelet must be select. However, there is no definite rule to guide how to choose the right wavelet until now due to sampled waves are unexpectable. Most of the researches are based on try and error approach. In this report, $\mathrm{db} 8, \mathrm{db} 9$, db10, sym7, sym8 were used to diagnosis broken rotor bars. According to Figure 11, 12, wavelet sym8 has the most obvious gap under 1, 2 and 3 broken bars.

\section{CONCLUSIONS}

In this paper, the proposed algorithm is applied to the stator current of a healthy and faulty induction motor. Two novel criterion functions are introduced to select the optimal wavelet to diagnose the broken rotor bars fault in induction machines. FFT based spectrum analysis is used to compare with wavelet analysis result to demonstrate these criterion functions have the ability to detect fault in induction motors under rate load. Moreover, even the number of broken bars can be diagnosed accurately. Both simulations and experiments can prove that increase of the load and broken bars is followed by a growth in harmonic components amplitude of a faulty induction motor.

\section{REFERENCES}

[1] Chow, Y M, "Motor fault detection and diagnosis," IEEE Industrial Electronics Newsletter, vol. 44, no. 4, pp. 4-7, 1997.

[2] Patton, R J and Chen, J, "Robustness in model-based fault diagnosis," In Concise Encyclopedia of Simulation and Modelling, (D Atherton, P Borne eds), Pergamon Press, pp. 379-392, January 1992.

[3] Radhika, S, et al., "Precise wavelet for current signature in $3 \varphi 1 \mathrm{M}$," Expert Systems with applications, vol. 37, no. 1, pp. 450-455, 2010.

[4] Riera-Guasp, M, et al., "A General Approach for the Transient Detection of Slip -Dependent Fault Components Based on the Discrete Wavelet Transform," IEEE Transactions on Industrial Electronics, vol. 55, no. 12, pp. 4167-4180, 2008.

[5] Siau, J, et al., "Broken Bar Detection in Induction Motors using Current and Flux Spectral Analysis," Australasian Universities Power Engineering Conference (AUPEC), Christchurch, New Zealand, 2003.

[6] Benbouzid, M.E.H, "A Review of Induction Motor Signature Analysis as a Medium for Faults Detection," IEEE Transactions on Industrial Electronics, vol. 47, no. 5, pp. 984-993, 2000.

[7] Da Silva, AA and Upadhyaya, B R, "Rotating machinery monitoring and diagnosis using short-time Fourier transform and wavelet techniques," Proc. 1997 Int. Conf. Maintenance and Reliability, 1997. 
[8] Douglas, H and Pillay, P, "The impact of wavelet selection on transient motor current signature analysis," IEEE International Conference on Electric Machines and Drives, San Antonio, Texas, USA, pp. 80-85, 2005.

[9] Ye, Z, Wu, B and Sadeghian, A, "Current signature analysis of induction motor mechanical faults by wavelet packet decomposition," IEEE Trans on Industrial Electronics, vol. 50, no. 6, pp. 1217-1227, 2003.

[10] Daviu, J Antonino, et al., "Validation of a new method for the diagnosis of rotor bar failures via wavelet transformation in industrial induction machines," IEEE Trans. Ind. Appl. vol. 42, no. 4, pp. 990-996, 2006.

[11] Arashloo, R S and Jalilian, A, "Design, Implementation and Comparison of Two Wavelet Based Methods for the Detection of Broken Rotor Bars in Three Phase Induction Motors," 1st Power Electronic \& Drive Systems \& Technologies Conference, PEDSTC, pp. 345-350, 2010.
[12] Sadri, H, "Induction Motor Broken Rotor Bar Fault Detection Using Wavelet Analysis," Master's Thesis, Iran University of Science \& Technology, 2004.

[13] Ponci, F, et al., "Diagnostic of a Faulty Induction Motor Drive via Wavelet Decomposition," IEEE Transactions on Instrumentation and Measurement, vol. 56, no. 6, pp. 2606-2615, 2007.

[14] Burrus, C S, Gopinath, R A and Guo, H, "Introduction to Wavelets and Wavelet Transforms. A Primer," Englewood Cliffs, NJ: Prentice-Hall, 1998.

[15] Zhang, J W, et al., "A Fault Diagnosis Approach for Broken Rotor Bars Based on EMD and Envelope Analysis," Journal of China University Mining \& Technology, vol. 17, no. 2, pp. 205-209, 2007. 